\title{
Crane-Heise syndrome
}

INSERM

\section{Source}

INSERM. (1999). Orphanet: an online rare disease and orphan drug data base. CraneHeise syndrome. ORPHA:1512

Crane-Heise syndrome is a very rare syndrome characterized by poorly mineralized calvarium, facial dysmorphism, vertebral abnormalities and absent clavicles. 